\title{
Experimental evaluation of helically coiled tube flocculators for turbidity removal in drinking water treatment units
}

\author{
Danieli Soares de Oliveira ${ }^{1 *}$ and Edmilson Costa Teixeira² \\ 'IFES - Federal Institute of Espírito Santo, Rodovia G. José Sette S/N Itacibá, Campus Cariacica, Cariacica-ES 29150-410, Brazil \\ ${ }^{2}$ UFES - Federal University of Espírito Santo, Av. Fernando Ferrari, S/N Goiabeiras, Vitória-ES 29075-910, Brazil
}

\section{ABSTRACT}

\begin{abstract}
The constant need to improve water treatment techniques allows for the emergence of new technologies for obtaining adequate water, both in terms of quality and quantity. In order to obtain an efficient, rapid and low-cost clarification system, this study proposes the use of helically coiled tubes (HCTs) as a coagulationflocculation reactor coupled with a conventional decanter system. Eighty-four (84) turbidity removal tests were performed to evaluate the proposed clarification system, while varying hydraulic and geometrical parameters in HCTs. Removal efficiency values higher than $80 \%$ were obtained (with a maximum removal efficiency of $86.2 \%$ ), presenting better results than systems using baffled tanks, which are traditionally applied for water treatment purposes in developing countries. In addition, significantly lower processing times (lower than $2 \mathrm{~min}$, about 10\% of baffled tank processing times) were observed for high efficiency process values, indicating that this clarification system can be useful in rational design of coagulationflocculation units. It should be noted that the turbidity removal efficiency results obtained (with a risingthen-decreasing behaviour over time) differ significantly from those obtained by the commonly used models for flocculation evaluation (with asymptotic behaviour over time), presenting a maximum absolute percentage deviation of $48.9 \%$, and indicating caution in the use of such models for alternative flocculation unit evaluation
\end{abstract}

Keywords: flocculation, drinking water, turbidity, turbidity removal efficiency, helically coiled tubes

\section{INTRODUCTION}

Suspended solids removal is an essential component of drinking water treatment. Such removal is commonly done in three steps which together comprise the clarification process: coagulation, flocculation and sedimentation/flotation.

Coagulation involves the dispersal of a coagulant into the mass flow by an intense agitation, usually measured by $G$, the mean velocity gradient, and producing particle destabilisation. After that, the destabilised particles are submitted to weak agitation to promote floc formation; this step is called flocculation. At the end, the flocs are separated from the water by sedimentation/flotation.

There are interesting studies dealing with the effect of $G$ on the size and structure of flocs formed during destabilisation/ aggregation (e.g., Bubakova and Pivokonsky, 2012; Lin et al., 2013; Polasek, 2007; Spicer et al., 1998). Furthermore, some studies evaluate the hydrodynamic behaviour in flocculators, aiming to better understand the process (Haarhoff and Van Der Walt, 2001; Sartori et al., 2015).

In developing countries it is common to use hydraulic flocculators, which promote agitation in water by imposing direction changes on the mass flow (Liu et al., 2004). Local velocity gradients caused by the sudden changes of direction can promote disruption of the flocs previously formed, reducing the efficiency of the process.

\footnotetext{
To whom all correspondence should be addressed.

+55 27 999050240; e-mail: danieli@ifes.edu.br

Received 13 March 2016; accepted in revised form 26 May 2017
}

In this context, several authors have suggested the use of helically coiled tubes to promote flocculation without abrupt changes in the direction of flow, but rather with smooth changes of direction throughout the unit (Al-Hashimi and Ashjyan, 1989; Elmaleh and Jabbouri, 1991; Gregory, 1981; Grohmann et al., 1981; Hameed et al., 1995; Thiruvenkatachari et al., 2002; Tse et al., 2011; Vaezi et al., 2011; Vigneswaran and Setiadi, 1986). These studies have shown that this flocculator, called the 'helically coiled tube flocculator - HCTF', promotes efficient floc formation with high velocity gradient values (due to its helical characteristic - with high head loss values) and low process times. Furthermore, HCTF is an easy-to-clean, lowcost and compact system, indicating that it is a good alternative for solid-liquid separation in the expansion of already existing units or in new drinking water facilities.

As an example, the flocculation time needed to have a residual turbidity under $5 \%$ in a baffled channel hydraulic flocculator is about $15-20 \mathrm{~min}$ for $Q=1.8 \mathrm{~m}^{3} / \mathrm{h}$ (McConnachie and Liu, 1999). Meanwhile, in a HCTF, about $1 \mathrm{~min}$ is needed to achieve the same residual turbidity, considering $Q=0.7 \mathrm{~m}^{3} / \mathrm{h}$ (Grohmann et al., 1981). This result emphasises the importance of evaluating the use of helically coiled tubes as flocculators in order to improve the clarification process.

Despite the large field of work already published, there is still a need for further experimental studies of the efficiency of turbidity removal in drinking water. In particular, the mathematical models commonly used to examine coagulation and flocculation processes (Argaman and Kaufman, 1970; Bratby et al., 1977; Camp and Stein, 1943; Fair and Gemmell, 1964; Harris et al., 1966; Schuetz and Piesche, 2002; Smoluchowski, 1917) have not yet been tested in this kind of treatment unit. 
This paper presents and analyses the experimental results for turbidity removal efficiency and processing time of a clarification system composed of a helically coiled tube flocculator (as a coagulation-flocculation reactor) coupled to a conventional decanter system, applied to water treatment systems. Furthermore, this study evaluates two mathematical models commonly used to estimate flocculation performance in order to recommend a tool for rational design of units for practical purposes.

\section{MATERIALS AND METHODS}

The methodology proposed in this study was divided into five parts: first, the experimental modelling apparatus is shown and described. After that, details of the reactor set-ups and the decanter system are described. and the main flocculation parameters used in this research are presented. Finally, the mathematical models commonly used to measure flocculator efficiency are described.

\section{Experimental modelling apparatus}

The experimental apparatus used is shown in Vigneswaran and Setiadi (1986), based on a complete cycle of the clarification system, composed of: (1) a reservoir of synthetic water; (2) a flow meter (flow controllers), (3) dosing pumps of chemical reagents, (4) pressure gauge connected at flocculator's input and output sections, (5) flocculator, (6) decanter system (settling tank) and (7) drain to the final disposal of the fluid.

Initially, water is pumped and mixed with clay (bentonite), resulting in a synthetic water. A mixer operates continuously

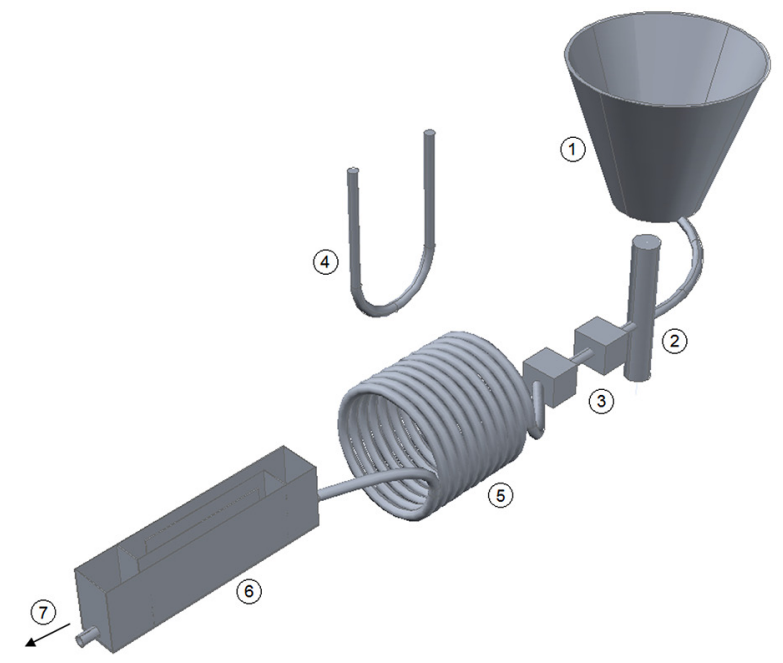

Figure 1

Schematic illustration of the hydraulic circuit: (1) a reservoir of synthetic water; (2) a flow meter (flow controllers), (3) dosing pumps of chemical reagents, (4) pressure gauge connected at flocculator's input and output sections, (5) flocculator, (6) decanter system (settling tank) and (7) drain to the final disposal of the fluid. to ensure that fluid characteristics are kept uniform, with $\mathrm{pH}$ and temperature values approximately equal to 6.0 and $22^{\circ} \mathrm{C}$, respectively. At the end of mixing, the effluent had an average turbidity of $50 \mathrm{UT}$, considered to be the initial turbidity value in all tests. After that, the flow rate is measured, and the coagulant (aluminium sulphate, for destabilisation of the particles) and alkalising agent (sodium hydroxide, for $\mathrm{pH}$ adjustment) are added by the dosing pumps located upstream of the flocculator. After the addition of these chemicals, the fluid passes through the flocculator (where head loss was measured in all tests) and goes to the settling tank, where sample collection took place in order to determine the final turbidity. The final disposal of the fluid is made at the end drain. The experimental uncertainty based on instrumental uncertainty was $10 \%$.

\section{Reactor set-up}

HCTF consists of a transparent and flexible polyvinyl chloride hose (PVC hose), coiled in a rigid PVC pipe. The hose used has a smooth internal surface with synthetic yarn reinforcement giveing high tenacity to ensure that there are no changes in the cross section along the reactor. The main features of the reactor are described in Figure 2.

Forty-eight (48) HCTF configurations were tested (24 HCTFs with two different flow rates), and their characteristics are described in Table 1. Six different arrangements are verified, and the distinguishing parameter is the reactors' length and, therefore, the flocculation process time.

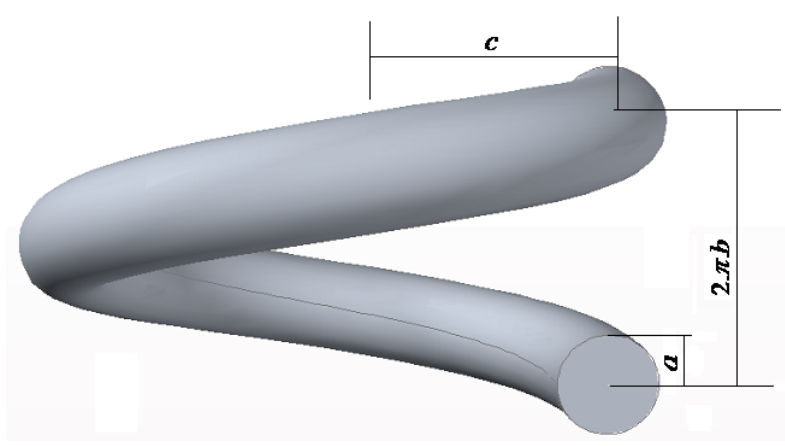

Figure 2

Geometric parameters in a helically coiled tube. $\boldsymbol{a}$ is the tube radius, $\boldsymbol{b}$ is the distance between consecutive passes divided by 2 and $c$ is the curvature radius. 


\begin{tabular}{|c|c|c|c|c|c|c|}
\hline \multicolumn{7}{|c|}{$\begin{array}{c}\text { TABLE } 1 \\
\text { Geometric and hydraulic characteristics of } 48 \text { HCTFs configurations. Parameters } a, b \text { and } c \text { are } \\
\text { defined in Figure } 2 ; L \text { is the HCTF length; and } Q \text { is flow rate }\end{array}$} \\
\hline Arrangement & HCTF & $a(\mathrm{~m})$ & $b(\mathrm{~m})$ & $c(\mathrm{~m})$ & $L(\mathrm{~m})$ & $Q\left(10^{-6} \mathrm{~m}^{3} \mathrm{~s}^{-1}\right)$ \\
\hline \multirow[t]{8}{*}{1} & 1 & 0.0048 & 0.0022 & 0.0568 & 2.63 & 16.7 \\
\hline & 2 & 0.0048 & 0.0022 & 0.0568 & 5.26 & 16.7 \\
\hline & 3 & 0.0048 & 0.0022 & 0.0568 & 10.53 & 16.7 \\
\hline & 4 & 0.0048 & 0.0022 & 0.0568 & 15.80 & 16.7 \\
\hline & 5 & 0.0048 & 0.0022 & 0.0568 & 21.07 & 16.7 \\
\hline & 6 & 0.0048 & 0.0022 & 0.0568 & 26.31 & 16.7 \\
\hline & 7 & 0.0048 & 0.0022 & 0.0568 & 31.58 & 16.7 \\
\hline & 8 & 0.0048 & 0.0022 & 0.0568 & 36.84 & 16.7 \\
\hline \multirow[t]{8}{*}{2} & 9 & 0.0048 & 0.0022 & 0.0568 & 2.63 & 33.3 \\
\hline & 10 & 0.0048 & 0.0022 & 0.0568 & 5.26 & 33.3 \\
\hline & 11 & 0.0048 & 0.0022 & 0.0568 & 10.53 & 33.3 \\
\hline & 12 & 0.0048 & 0.0022 & 0.0568 & 15.80 & 33.3 \\
\hline & 13 & 0.0048 & 0.0022 & 0.0568 & 21.07 & 33.3 \\
\hline & 14 & 0.0048 & 0.0022 & 0.0568 & 26.31 & 33.3 \\
\hline & 15 & 0.0048 & 0.0022 & 0.0568 & 31.58 & 33.3 \\
\hline & 16 & 0.0048 & 0.0022 & 0.0568 & 36.84 & 33.3 \\
\hline \multirow[t]{8}{*}{3} & 17 & 0.0064 & 0.0027 & 0.0584 & 2.96 & 16.7 \\
\hline & 18 & 0.0064 & 0.0027 & 0.0584 & 5.92 & 16.7 \\
\hline & 19 & 0.0064 & 0.0027 & 0.0584 & 8.88 & 16.7 \\
\hline & 20 & 0.0064 & 0.0027 & 0.0584 & 11.84 & 16.7 \\
\hline & 21 & 0.0064 & 0.0027 & 0.0584 & 14.80 & 16.7 \\
\hline & 22 & 0.0064 & 0.0027 & 0.0584 & 17.76 & 16.7 \\
\hline & 23 & 0.0064 & 0.0027 & 0.0584 & 20.72 & 16.7 \\
\hline & 24 & 0.0064 & 0.0027 & 0.0584 & 23.68 & 16.7 \\
\hline \multirow[t]{8}{*}{4} & 25 & 0.0064 & 0.0027 & 0.0584 & 2.96 & 33.3 \\
\hline & 26 & 0.0064 & 0.0027 & 0.0584 & 5.92 & 33.3 \\
\hline & 27 & 0.0064 & 0.0027 & 0.0584 & 8.88 & 33.3 \\
\hline & 28 & 0.0064 & 0.0027 & 0.0584 & 11.84 & 33.3 \\
\hline & 29 & 0.0064 & 0.0027 & 0.0584 & 14.80 & 33.3 \\
\hline & 30 & 0.0064 & 0.0027 & 0.0584 & 17.76 & 33.3 \\
\hline & 31 & 0.0064 & 0.0027 & 0.0584 & 20.72 & 33.3 \\
\hline & 32 & 0.0064 & 0.0027 & 0.0584 & 23.68 & 33.3 \\
\hline \multirow[t]{8}{*}{5} & 33 & 0.0080 & 0.0032 & 0.060 & 1.89 & 33.3 \\
\hline & 34 & 0.0080 & 0.0032 & 0.060 & 3.79 & 33.3 \\
\hline & 35 & 0.0080 & 0.0032 & 0.060 & 5.68 & 33.3 \\
\hline & 36 & 0.0080 & 0.0032 & 0.060 & 7.58 & 33.3 \\
\hline & 37 & 0.0080 & 0.0032 & 0.060 & 9.47 & 33.3 \\
\hline & 38 & 0.0080 & 0.0032 & 0.060 & 11.37 & 33.3 \\
\hline & 39 & 0.0080 & 0.0032 & 0.060 & 13.26 & 33.3 \\
\hline & 40 & 0.0080 & 0.0032 & 0.060 & 15.16 & 33.3 \\
\hline \multirow[t]{8}{*}{6} & 41 & 0.0080 & 0.0032 & 0.060 & 1.89 & 66.7 \\
\hline & 42 & 0.0080 & 0.0032 & 0.060 & 3.79 & 66.7 \\
\hline & 43 & 0.0080 & 0.0032 & 0.060 & 5.68 & 66.7 \\
\hline & 44 & 0.0080 & 0.0032 & 0.060 & 7.58 & 66.7 \\
\hline & 45 & 0.0080 & 0.0032 & 0.060 & 9.47 & 66.7 \\
\hline & 46 & 0.0080 & 0.0032 & 0.060 & 11.37 & 66.7 \\
\hline & 47 & 0.0080 & 0.0032 & 0.060 & 13.26 & 66.7 \\
\hline & 48 & 0.0080 & 0.0032 & 0.060 & 15.16 & 66.7 \\
\hline
\end{tabular}




\section{Decanter system}

In order to evaluate the solid liquid separation and the turbidity removal efficiency, each HCTF was coupled to a single settling tank, as shown in Fig. 3.

To ensure that the geometric and hydraulic features of the decanter do not hinder the final turbidity removal efficiency of the process, a single decanter (with the same flow rate) was used in all experiments. The sedimentation velocity used in all tests was $0.21 \mathrm{~cm} / \mathrm{s}$, according to Di Bernardo and Dantas (2005).

The decanter design was based on retention time, flow velocity and input/output devices, following the methodology described by Di Bernardo and Dantas (2005). The material used for outside walls was polystyrene and the baffles were built with plastic sheets $1.5 \mathrm{~mm}$ thick. Table 2 shows the main geometrical characteristics of the decanter.

\section{Main flocculation parameters}

This section presents the main flocculation parameters used (Table 3) The Reynolds number was calculated to characterise flow regimes - in all cases flow was laminar (Cioncolini and Santini, 2006; Oliveira and Teixeira, 2016).

\section{Mathematical models}

In general, flocculation is commonly measured by the use of mathematical models which consider hydraulic parameters and water quality information. There is no specific model given in the literature to evaluate flocculation in HCTFs. Therefore, in this study, Argaman and Kaufman (1970) and Bratby et al. (1977) models (Equations 1 and 2, respectively) were evaluated due to their extensive utilisation in unit design (Haarhoff et al., 1996; Moruzzi and Oliveira, 2012).

$$
\begin{aligned}
& \frac{N_{0}}{N_{1}}=\frac{1+K_{A} \cdot G \cdot t}{1+K_{B} \cdot G^{2} \cdot t} \\
& \frac{N_{0}}{N_{1}}=\left[\frac{K_{B}}{K_{A}} G+\left(1-\frac{K_{B}}{K_{A}} G\right) e^{-K_{A} G t}\right]^{-1}
\end{aligned}
$$

\begin{tabular}{|l|c|}
\hline \multicolumn{2}{|c|}{ Main geometrical characteristics of the decanter } \\
\hline Geometrical parameter & Value \\
\hline Reactor volume & $3.76 \mathrm{~L}$ \\
\hline Baffle length & $40 \mathrm{~cm}$ \\
\hline Reactor height & $15 \mathrm{~cm}$ \\
\hline Inlet weir height & $10 \mathrm{~cm}$ \\
\hline Outlet weir height & $8 \mathrm{~cm}$ \\
\hline Number of baffles & 3 \\
\hline Baffle width & $3.3 \mathrm{~cm}$ \\
\hline
\end{tabular}

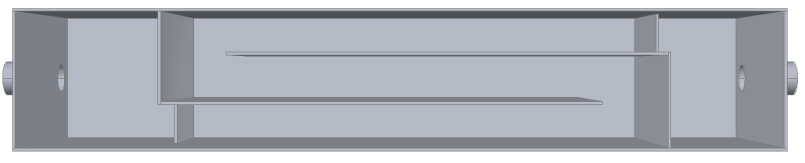

Figure 3

Schematic illustration of the settling tank

where: $N_{0}$ and $N_{1}$ are initial and final concentrations, respectively (in this paper initial and final concentrations are represented by initial and final turbidity values - as presented in Bratby et al. (1977)). $K_{A}$ and $K_{B}$ are constants obtained from experimental results and Equations 1 and 2, considering the values of $N_{1}$ and $t$ related to the maximum value of the experimental curve (where $\left.\mathrm{d} N_{1} / \mathrm{d} t=0\right)$. Based on values of $K_{A}, K_{B}, N_{0}$ and $G$ (constants), a relationship between $N_{1}$ and $t$ is obtained.

\section{RESULTS AND DISCUSSION}

First, the coagulation diagram results are shown and described. After that, the experimental results for turbidity removal efficiency and processing time of HCTFs are presented and analysed. Finally, two mathematical models were used together to estimate flocculation performance.

\begin{tabular}{|l|l|c|}
\hline \multicolumn{2}{|c|}{ Main flocculation parameters } \\
\hline Parameter & Description & \multicolumn{1}{|c|}{ Equation } \\
\hline $\begin{array}{l}\text { Turbidity removal } \\
\text { efficiency }\end{array}$ & $\begin{array}{l}\text { In all tests, the turbidity removal efficiency } \\
\text { was obtained to verify the percentage of the } \\
\text { decanted flocculated particles, depending on } \\
\text { the total solid particles. }\end{array}$ & $E f .(\%)=\left[1-\left(\frac{\text { remaining turbidity }}{\text { initial turbidity }}\right)\right] \times 100$ \\
\hline Retention time & $\begin{array}{l}\text { The theoretical detention time was obtained } \\
\text { by the ratio of the reactor volume }(\text { Vol }) \text { and } \\
\text { the flow rate }(Q) .\end{array}$ & $t=\frac{\text { Vol }}{Q}$ \\
\hline $\begin{array}{l}\text { Mean velocity } \\
\text { gradient }\end{array}$ & $\begin{array}{l}\text { The head loss }(h f) \text { measured along the unit } \\
\text { by a manometer and the retention time were } \\
\text { used to obtain the velocity gradient }(G) .\end{array}$ & $G=\sqrt{\frac{\rho \cdot g \cdot h f}{\mu \cdot t}}$ \\
\hline Reynolds number & $\begin{array}{l}\text { The Reynolds number was obtained } \\
\text { from fluid characteristics }(\rho \text { and } \mu), \\
\text { geometrical characteristics }(a) \text { and hydraulic } \\
\text { characteristics }(v-\text { mean velocity). }\end{array}$ & $R e=\frac{\rho \cdot v \cdot 2 a}{\mu}$ \\
\hline
\end{tabular}




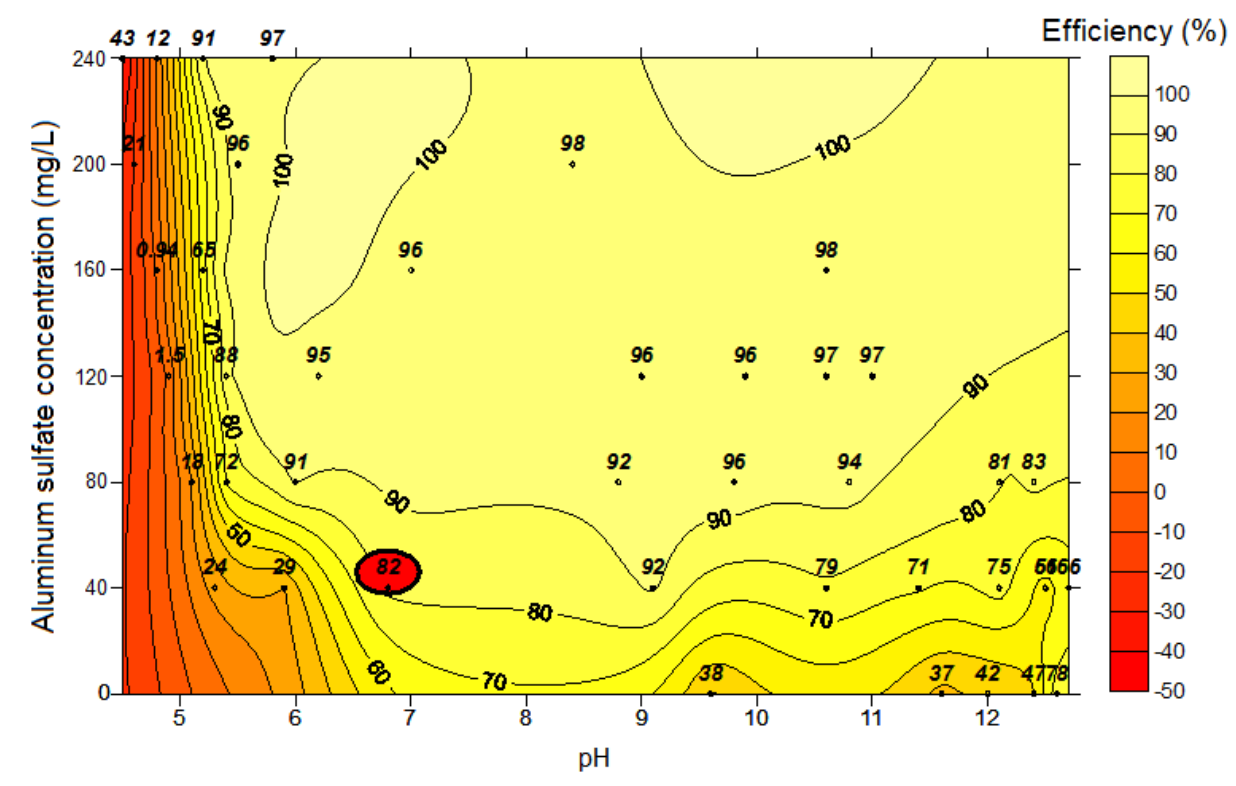

Figure 4

Coagulation diagram: $\mathbf{G}=250 \mathrm{~s}^{-1}$

\section{Coagulation diagram}

A coagulation diagram was used to select the appropriate coagulant dosage for a given application. Thirty-six (36) tests were performed in order to build the coagulation diagram, shown in Fig. 4.

From Fig. 4, one can note that the values for turbidity removal efficiency varied in the range $1 \%-98 \%$. Furthermore, $60 \%$ of the tests gave values for turbidity removal efficiency higher than $80 \%$, with $43 \%$ of tests giving a turbidity removal efficiency higher than $90 \%$, indicating a remaining turbidity of less than 5 UT.

In the performed tests, the coagulant and alkalising dosages were chosen based on three criteria: (i) minimise the use of chemical agents; (ii) the $\mathrm{pH}$ of the final solution should be near to that recommended in the literature (from 6 to 8 ); and (iii) the chemical dosages should allow the solution to be sensitive to variations in HCTF geometrical characteristics.

Based on these criteria, the operational point was chosen, considering a dosage of aluminium sulphate equal to $40 \mathrm{mg} / \mathrm{L}$ and a dosage of sodium hydroxide equal to $50 \mathrm{mg} / \mathrm{L}$. This operational point presented a turbidity removal efficiency equal to $82 \%$, given an initial turbidity of 50 UT (highlighted in red in Fig. 4). The $\mathrm{pH}$ of the final solution was equal to 6.8 and the remaining turbidity was equal to 9.4 UT. These dosages of aluminium sulphate and sodium hydroxide were kept unchanged for all of the performed analyses.

\section{HCTF experimental results}

The experimental modelling results obtained for the 48 HCTF configurations are shown in Fig. 5. The results for turbidity removal efficiency versus flocculation time are shown for the six studied arrangements defined in Table 1 . In addition, the mean velocity gradient results, maximum turbidity removal efficiency value and respective process time are shown in
Fig. 5. The mean error value for turbidity removal efficiency measurements was $1.5 \%$.

From Fig. 5, the values of turbidity removal efficiency have a rising-then-decreasing behaviour with increase in HCTF flocculation time. With this, maximum turbidity removal efficiency regions may be verified for specific process times, and such process times are dependent on units' hydraulic and geometric parameters. These parameters influence the hydrodynamic behaviour of the unit, which strongly affects the interaction between particles present in a liquid mass. This interaction is favoured in helically coiled tubes, whereas the presence of a secondary flow in cross section promotes a major interaction between particles previously destabilised, favouring the formation of flocs (Sartori et al., 2015). However, the flow's behaviour can promote destabilisation in flocs previously formed due to the shear stresses verified in helical flows, reducing the efficiency of the process over time.

When the maximum turbidity removal efficiency is evaluated with mean velocity gradients (considering the same geometric characteristics and different flow rates), one notes that the best results were obtained for the lowest mean velocity gradient values (Fig. 6). These results show that higher velocity gradient values and, consequently, higher shear stress values, can promote a decrease in the efficiency of the process. For the cases evaluated in this study, the increase in the mean velocity gradient is exclusively due to the increase in flow rate, whereas the other characteristics were held constant. This result confirms that changes in flocculation unit flow should be evaluated with caution, since these changes can significantly influence the interaction between the particles and consequently in solid-liquid separation.

The rising-then-decreasing behaviour verified for turbidity removal efficiency with increase in HCTF flocculation time is not verified in mathematical models commonly used to estimate the relationship between initial and final turbidity. In particular, models presented in Argaman and Kaufman (1970) 

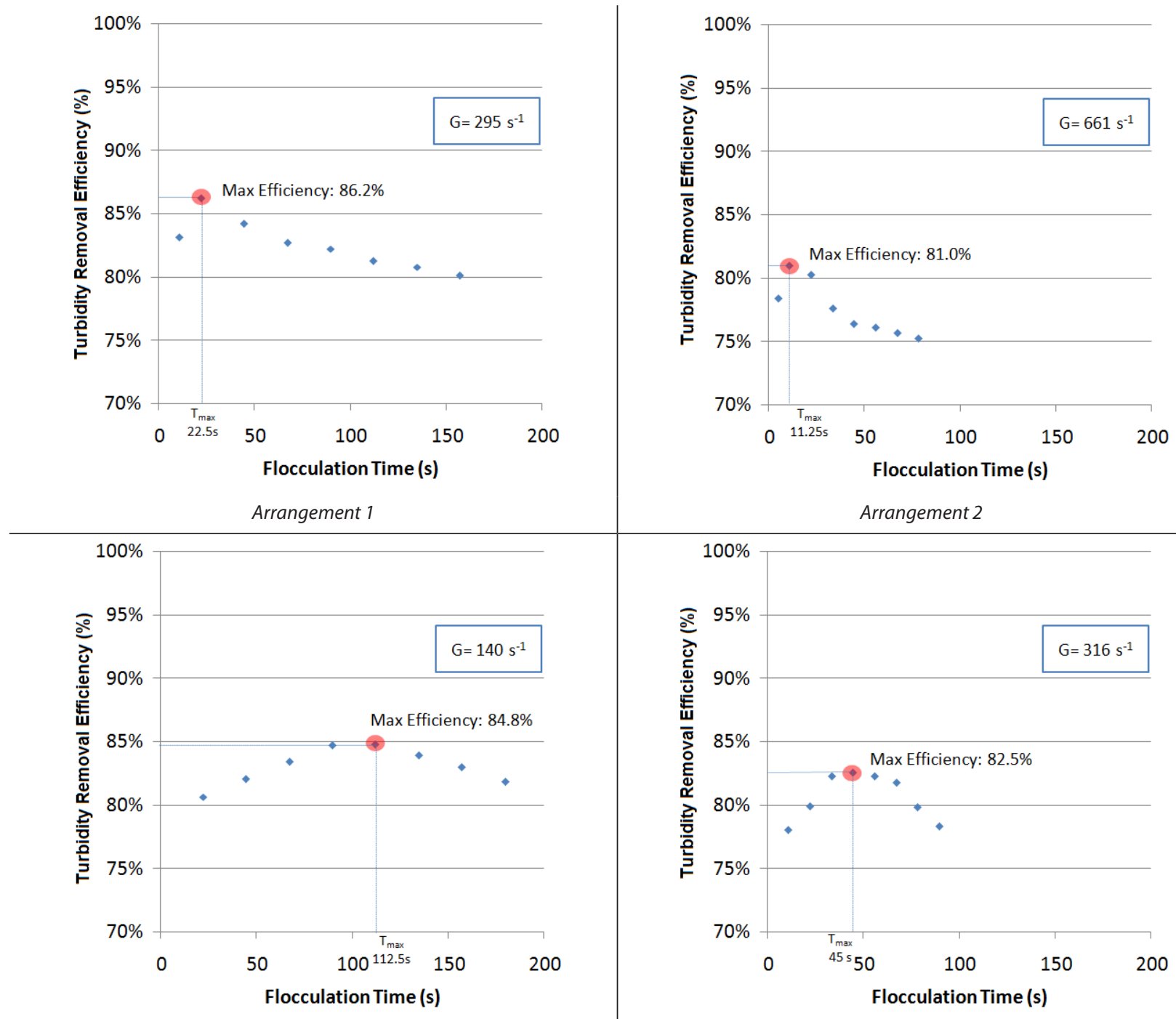

Arrangement 2

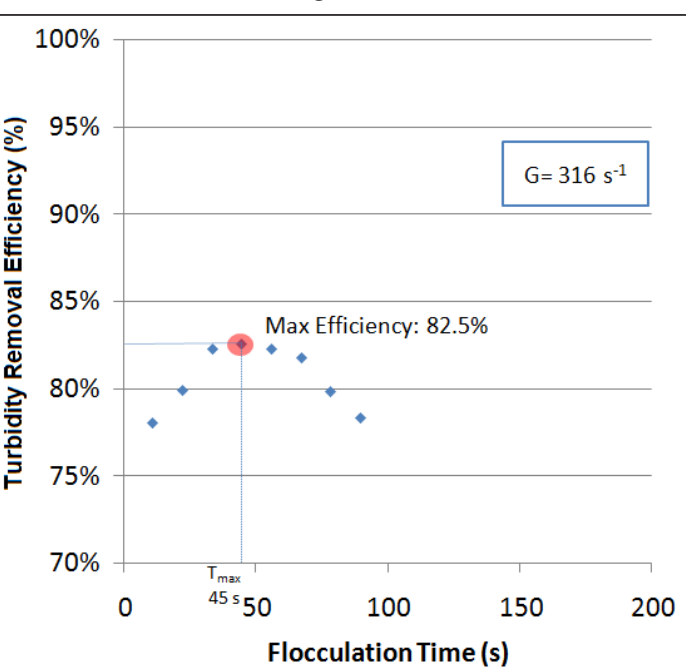

Arrangement 3

Arrangement 4

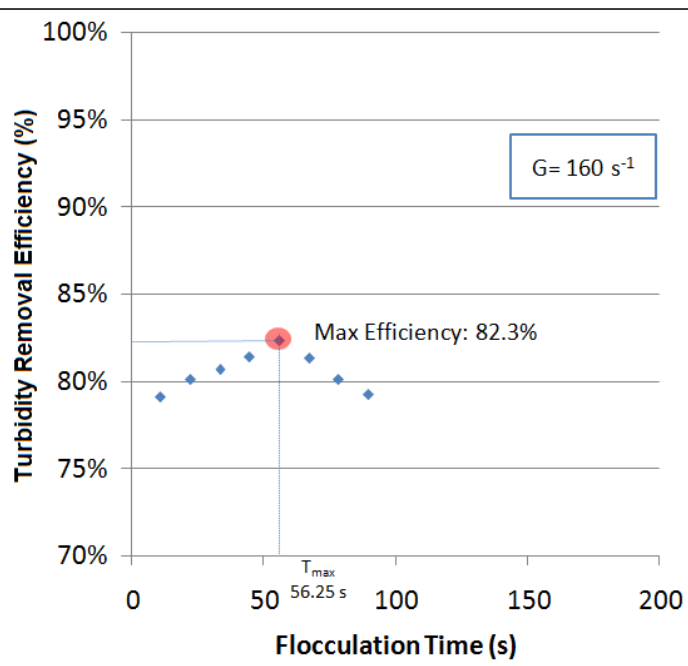

Arrangement 5

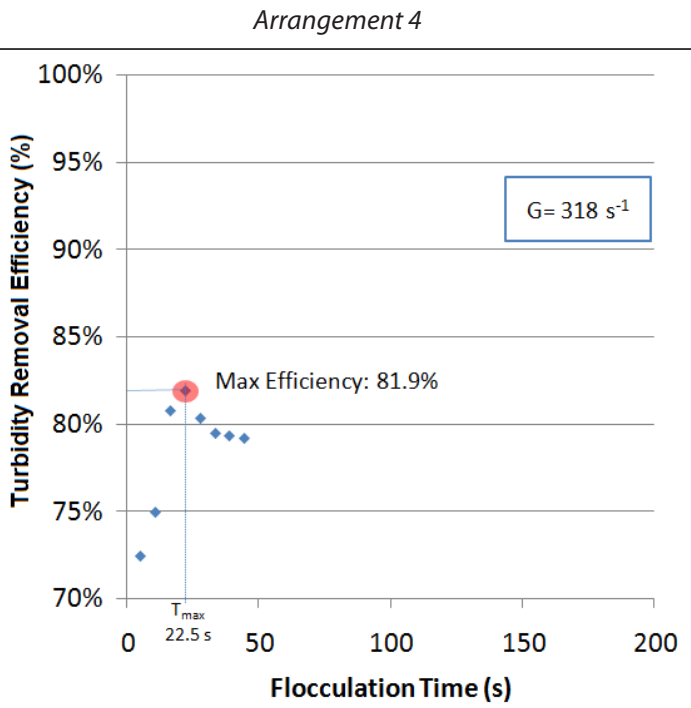

Arrangement 6

Figure 5

Relationship between turbidity removal efficiency and flocculation time for 6 arrangements 


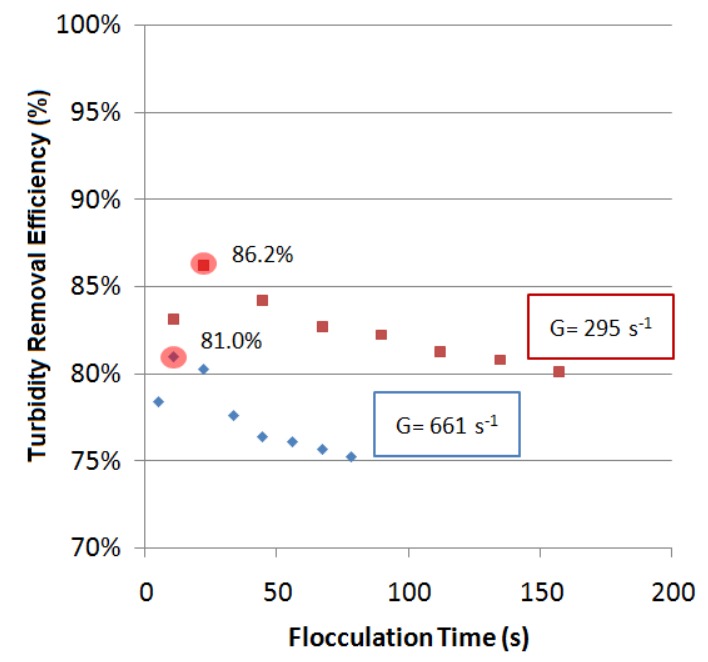

(a)

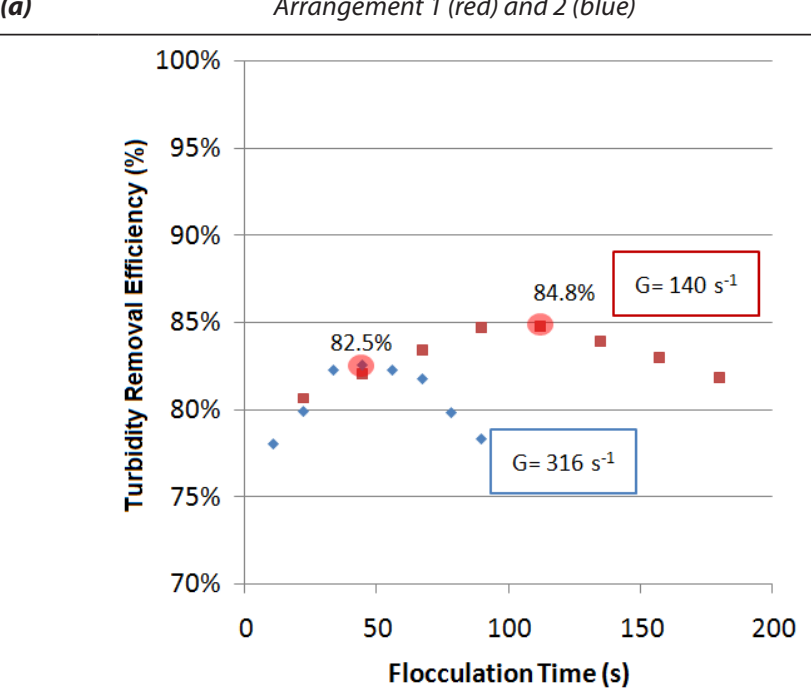

(b)

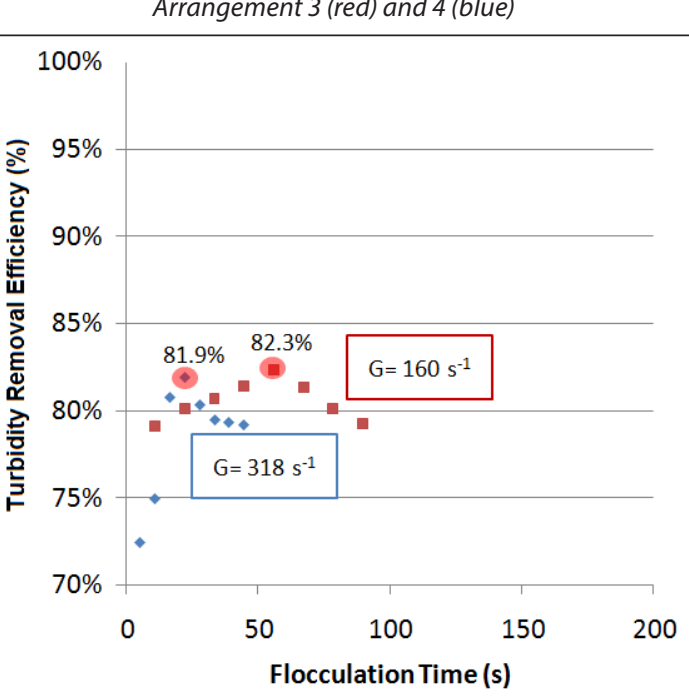

(c)

Arrangement 5 (red) and 6 (blue)

Figure 6

Maximum turbidity removal efficiency versus mean velocity gradients and Bratby et al. (1977) (described in Materials and Methods), have an asymptotic characteristic, shown in Appendix 1.

In order to analyse such models, as applied to HCTFs, Fig. 7 presents the results obtained for Arrangement 2 (Table 1: HCTF 9 to HCTF 16) in a dimensionless form (the process time was normalised using maximum process time).

It can be noted in Fig. 7 that the functions evaluated deviate considerably from the values obtained experimentally. In addition, from the evaluation of other configurations tested in this study, the maximum and average percentage deviations values can reach $48 \%$ and $27 \%$, respectively, as shown in Table 4.

Results obtained from models presented in Argaman and Kaufman (1970) and Bratby et al. (1977) can be qualitatively and quantitatively evaluated. Quantitatively, a significant deviation is observed in the maximum absolute percentage deviation values (since experimental uncertainty is 10\%). Therefore, the average absolute percentage deviation values were not acceptable in most cases. Qualitatively, the asymptotic characteristic observed in Fig. 7 differs significantly from the rising-decreasing behaviour experimentally verified, indicating that these models are not adhering to the assessed physical process. Thus, there is a need to obtain models that can adequately predict the behaviour of values for turbidity removal efficiency in HCTFs, since in both cases the models tested were not adequate to estimate flocculation process efficiency.

\section{TABLE 4}

Maximum and average percentage deviations obtained using Argaman and Kaufman (1970) and Bratby et al. (1977) models

\begin{tabular}{|c|c|c|c|c|}
\hline \multirow{2}{*}{ Arrangement } & \multicolumn{4}{|c|}{ Absolute percentage deviation } \\
\cline { 2 - 5 } & Argaman and Kaufman (1970) & \multicolumn{2}{c|}{ Bratby et al. (1977) } \\
\cline { 2 - 5 } & Maximum & Average & Maximum & Average \\
\hline 1 & $35.5 \%$ & $16.8 \%$ & $26.7 \%$ & $11.6 \%$ \\
\hline 2 & $48.9 \%$ & $27.4 \%$ & $30.2 \%$ & $16.3 \%$ \\
\hline 3 & $15.3 \%$ & $3.6 \%$ & $32.2 \%$ & $6.7 \%$ \\
\hline 4 & $30.1 \%$ & $8.6 \%$ & $31.8 \%$ & $9.9 \%$ \\
\hline 5 & $27.4 \%$ & $11.3 \%$ & $36.8 \%$ & $14.3 \%$ \\
\hline 6 & $28.4 \%$ & $13.5 \%$ & $35.0 \%$ & $13.1 \%$ \\
\hline
\end{tabular}

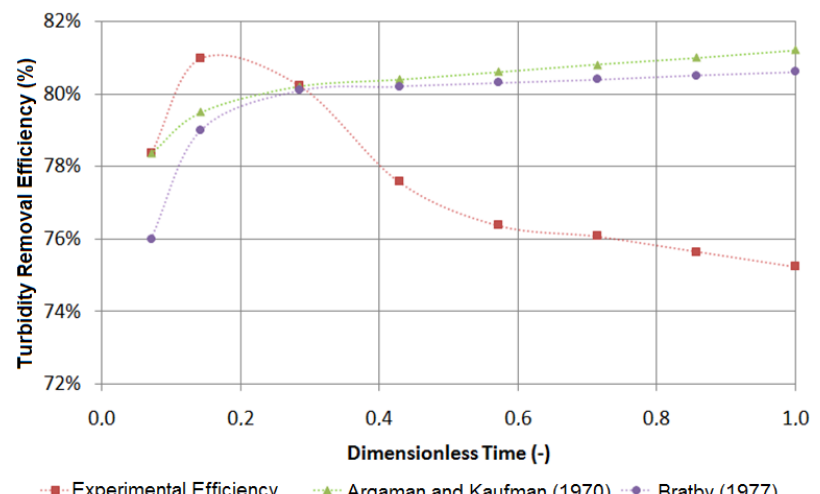

Figure 7

Turbidity removal efficiency obtained (a) experimentally, (b) from model presented in Argaman and Kaufman (1970) and (c) from model presented in Bratby et al. (1977) 


\section{CONCLUSION}

The use of helically coiled tubes as a coagulation-flocculation reactor coupled to a conventional decanter system was evaluated experimentally in this study, with the aim of water clarification. A rising-then-decreasing behaviour was verified for turbidity removal efficiency with the increase in HCTF flocculation time, indicating that it is possible to obtain maximum-removal turbidity efficiency values for specific reactor characteristics. Removal efficiency values higher than $80 \%$ were obtained (with a maximum removal efficiency value of $86.2 \%$ ), presenting better results than systems using baffled tanks, which are traditionally applied for water treatment purposes in developing countries. Additionally, significantly lower processing times (lower than $2 \mathrm{~min}$, about $10 \%$ of baffled tank processing times) were observed for high efficiency process values, indicating that this kind of flocculator can be promising for use in clarification processes. Also, it was verified that the most efficient results were obtained for the HCTFs with lowest mean velocity gradients, indicating that higher velocity gradients and, consequently, higher shear stress values, result in decreases in efficiency. Lastly, two mathematical models extensively used in unit design - Argaman and Kaufman (1970) and Bratby et al. (1977) - were evaluated and did not present good results (showing a maximum absolute percentage deviation of $48.9 \%$ ). This suggests the need for development of a non-asymptotic model that can satisfactorily estimate the rising-then-decreasing efficiency behaviour over time.

\section{ACKNOWLEDGMENTS}

The authors would like to thank the institutional and financial support from Federal Institute of Espírito Santo (IFES), Federal University of Espírito Santo (UFES), Coordination for the Improvement of Higher Education Personnel (CAPES) and National Counsel of Technological and Scientific Development (CNPq).

\section{REFERENCES}

AL-HASHIMI MAI and ASHJYAN ASK (1989) Effectiveness of helical pipes in the flocculation process of water Filtr. Sep. 26 (6) 422-429.

ARGAMAN Y and KAUFMAN WJ (1970) Turbulence and flocculation. J. Sanit. Eng. Div. Proc. Am. Soc. Civ. Eng. 96 (SA 2) 223-241.

BRATBY J, MILLER MW and MARAIS GR (1977) Design of flocculation systems from batch test data. Water SA 3 (4) 173-182.

BUBAKOVA P and PIVOKONSKY M (2012) The influence of velocity gradient on properties and filterability of suspension formed during water treatment. Sep. Purif. Technol. 92 161-167. https://doi. org/10.1016/j.seppur.2011.09.031

CAMP TR and STEIN PC (1943) Velocity gradients and internal work in fluid motion. J. Boston Soc. Civ. Eng. 30 219-237.

CIONCOLINI A and SANTINI L (2006) An experimental investigation regarding the laminar to turbulent flow transition in helically coiled pipes. Exp. Therm. Fluid Sci. 30 367-380. https:// doi.org/10.1016/j.expthermflusci.2005.08.005

DI BERNARDO L and DANTAS ADB (2005) Water Treatment Methods and Techniques. (In Portuguese.) RIMA, São Paulo.

ELMALEH S and JABBOURI A (1991) Flocculation energy requirement. Water Res. 25 (8) 939-943. https://doi. org/10.1016/0043-1354(91)90141-C

FAIR GM and GEMMELL RS (1964) A mathematical model of coagulation. J. Colloid Sci. $19360-372$. https://doi. org/10.1016/0095-8522(64)90037-6
GREGORY J (1981) Particle interactions in flowing suspensions. Adv. Colloid Interface Sci. 17 (1) 149-160. https://doi. org/10.1016/0001-8686(82)80016-X

GROHMANN A, REITER M and WIESMANN U (1981) New flocculation units with high efficiency. Water Sci. Technol. 13 (11/12) 567-573.

HAARHOFF J, VAN BEEK JC and VAN ZYL HJ (1996) Practical application of the Argaman-Kaufman flocculation model. In: Biennial Conference and Exhibition, Water Institute of Southern Africa, 20-23 May 1996, Port Elizabeth.

HAARHOFF J and VAN DER WALT JJ (2001) Towards optimal design parameters for around-the-end hydraulic flocculators. J. Water Suppl. Res. Technol.-AQUA 10 149-159.

HAMEED MS, MUHAMMED TJ and SAPRE AA (1995) Improved technique for river water flocculation. Filtr. Sep. 32 (2) 63-68. https://doi.org/10.1016/S0015-1882(97)84021-9

HARRIS HF, KAUFMAN WJ and KRONE RB (1966) Orthokinect flocculation in water purification. J. Sanit. Eng. Div.; Proc. ASCE 92 (SA6) 95-111.

LIN J-L, PAN JR and HUANG C (2013) Enhanced particle destabilization and aggregation by flash-mixing coagulation for drinking water treatment. Sep. Purif. Technol. 115 145-151. https:// doi.org/10.1016/j.seppur.2013.05.013

LIU J, CRAPPER M and MCCONNACHIE GL (2004) An accurate approach to the design of channel hydraulic flocculators. Water Res. 38 875-886. https://doi.org/10.1016/j.watres.2003.10.014

MCCONNACHIE GL and LIU J (1999) Design of baffled hydraulic channels for turbulence-induced flocculation. Water Res. 34 1886-1896. https://doi.org/10.1016/S0043-1354(99)00329-2

MORUZZI R and OLIVEIRA S (2012) Mathematical modeling and analysis of the flocculation process in chambers in series. Bioprocess Biosyst. Eng. 36 (3) 357-363. https://doi.org/10.1007/ s00449-012-0791-4

OLIVEIRA DSD and TEIXEIRA EC (2016) Comparison between critical Reynolds number estimation models applied to helically coiled tubes flocculators. (In Portuguese.) In: XVII Luso-Brazilian Symposium on Sanitary and Environmental Engineering SILUBESA, ABES, 6-8 June 2016, Florianópolis.

POLASEK P (2007) Differentiation between different kinds of mixing in water purification - back to basics. Water SA 33 (2) 249-252.

SARTORI M, OLIVEIRA DS, TEIXEIRA EC, RAUEN WB and REIS NC (2015) CFD modelling of helically coiled tubes for velocity gradient assessment. J. Braz. Soc. Mech. Sci. Eng. 37 (1) 187-198. https://doi.org/10.1007/s40430-014-0141-3

SCHUETZ S and PIESCHE M (2002) A mathematical model of coagulation processes. Sep. Purif. Technol. 26 (1) 61-68. https://doi. org/10.1016/S1383-5866(01)00117-4

SMOLUCHOWSKI M (1917) Versuch einer mathematischen Theorie der Koagulationskinetik kolloider Lösungen. Z. Phys. Chem. 92 129-168

SPICER PT, PRATSINIS SE, RAPER J, AMAL R, BUSHELL G and MEESTERS G (1998) Effect of shear schedule on particle size, density and structure during flocculation in stirred tanks. Powder Technol. 97 (1) 26-34. https://doi.org/10.1016/ S0032-5910(97)03389-5

THIRUVENKATACHARI R, NGO HH, HAGARE P, VIGNESWARAN S and AIM RB (2002) Flocculation-cross-flow microfiltration hybrid system for natural organic matter (NOM) removal using hematite as a flocculent. Desalination 147 (1) 83-88. https://doi.org/10.1016/S0011-9164(02)00580-5

TSE IC, SWETLAND K, WEBER-SHIRK ML and LION LW (2011) Method for quantitative analysis of flocculation performance. Water Res. 45 (10) 3075-3084. https://doi.org/10.1016/j. watres.2011.03.021

VAEZI GF, SANDERS RS and MASLIYAH JH (2011) Flocculation kinetics and aggregate structure of kaolinite mixtures in laminar tube flow. J. Colloid Interf. Sci. 355 (1) 96-105. https://doi. org/10.1016/j.jcis.2010.11.068

VIGNESWARAN S and SETIADI T (1986) Flocculation study on spiral flocculator. Water Air Soil Pollut. 29 (2) 165-188. https://doi. org/10.1007/bf00208407 


\section{APPENDIX 1}

As an example, the asymptotic characteristic of Argaman and Kaufman (1970)'s model can be easily verified by an absence of inflection point in its equation:

$$
\begin{aligned}
& \frac{N_{0}}{N_{1}}=\frac{1+K_{A} \cdot G \cdot t}{1+K_{B} \cdot G^{2} \cdot t} \\
& \frac{d\left(N_{0} / N_{1}\right)}{d t}=0 \\
& \frac{\left(1+K_{B} G^{2} t\right) K_{A} G-\left(1+K_{A} G t\right) K_{B} G^{2}}{\left(1+K_{B} \cdot G^{2} \cdot t\right)^{2}}=0 \\
& \left(1+K_{B} G^{2} t\right) K_{A} G=\left(1+K_{A} G t\right) K_{B} G^{2} \\
& K_{A} G+K_{A} K_{B} G^{3} t=K_{B} G^{2}+K_{A} K_{B} G^{3} t \\
& t=\frac{\left(K_{B} G^{2}-K_{A} G\right)}{0}
\end{aligned}
$$

And a constant value for the ratio $N_{0} / N_{1}$ when $\lim _{t \rightarrow \infty}\left(N_{0} / N_{1}\right)$ :

$$
\begin{aligned}
& \frac{N_{0}}{N_{1}}=\frac{1+K_{A} \cdot G \cdot t}{1+K_{B} \cdot G^{2} \cdot t} \\
& \lim _{t \rightarrow \infty}\left(N_{0} / N_{1}\right)=\lim _{t \rightarrow \infty}\left(\frac{1+K_{A} \cdot G \cdot t}{1+K_{B} \cdot G^{2} \cdot t}\right)
\end{aligned}
$$

Appling L'Hôpital's rule:

$$
\lim _{t \rightarrow \infty}\left(N_{0} / N_{1}\right)=\frac{K_{A} G}{K_{B} G^{2}}=\frac{K_{A}}{K_{B} G}
$$

